\title{
Régimen local y Estatutos de Autonomía*
}

\author{
Luis Ortega \\ Catedrático de Derecho Administrativo \\ Universidad de Castilla-La Mancha
}

\begin{abstract}
Sumario: I. LA INOPORTUNIDAD E INCONVENIENCIA DE LA INTERIORIZACIÓN AUTONÓMICA DEL RÉGIMEN LOCAL. II. LA DISCUTIBLE CONSTRUCCIÓN DE LOS ESTATUTOS DE AUTONOMÍA COMO SUBCONSTITUCIONES TERRITORIALES INTEGRANDO A LOS ENTES LOCALES COMO PARTE DE LAS INSTITUCIONES AUTONÓMICAS. III. LA AMPLIACIÓN DEL MARCO COMPETENCIAL AUTONÓMICO EN MATERIA DE RÉGIMEN LOCAL MEDIANTE LA REMODELACIÓN DE LOS ESTATUTOS DE AUTONOMÍA.
\end{abstract}

\section{LA INOPORTUNIDAD E INCONVENIENCIA DE LA INTERIORIZACIÓN AUTONÓMICA DEL RÉGIMEN LOCAL}

La propuesta que es el objeto de análisis de estas páginas se puede concretar en la idea de la interiorización del régimen local en el ámbito competencial e institucional de las Comunidades Autónomas.

Esta propuesta conocida ya de antes a través de muchos trabajos no ha sido plenamente compartida por la doctrina, ni por la legislación, ni por la jurisprudencia del Tribunal Constitucional. Las cuales, en cambio, incluso han detectado o elaborado, como una de las principales peculiaridades de nuestro modelo constitucional de descentralización política, las denominadas «tres patas» (Estado-Comunidades Autónomas-Entes Locales) en las que se asienta el funcionamiento y la organización territorial del Estado en su conjunto.

Hay un primer tema de debate, que es el de la oportunidad o conveniencia de la implantación de dicho modelo de interiorización, que apenas se discute y que, sin embargo, es tan relevante o más que el de su posible encaje constitucional.

En alguna ocasión he señalado ${ }^{1}$ que muchas de las discordancias de nuestro modelo legislativo de régimen local derivan del hecho de tener que situarse

\footnotetext{
* Una primera versión de este trabajo se publicó en el libro colectivo "La Reforma Estatutaria de la Administración Local”, CEPC. Madrid,2006. En esta ocasión se ha modificado esencialmente el tercer apartado del trabajo.

${ }^{1}$ ORTEGA, «Diferenciación frente a uniformidad en la organización territorial local», Anuario del Gobierno Local 1999/2000, pp.77 y ss.
} 
éste dentro de dos lógicas. La lógica tradicional de nuestro régimen local es herencia francesa, a través de la articulación del ente local dentro de la voluntad general del Estado, con la construcción del concepto de pouvoir municipal y la consiguiente relación entre intereses propios y competencias propias, los poderes de control y vigilancia de la Administración periférica del Estado, etc.

Dentro de esa construcción jacobina, en nuestro debate histórico, y por influencia del conocimiento que tuvieron los ilustrados exiliados a Inglaterra del selfgovernment del municipalismo inglés, se introdujo la aspiración democrática de que los poderes locales fuesen elegidos por los vecinos.

La autonomía local tenía, así, en el discurso político del XIX un contenido más orientado a la configuración democrática del poder que a una forma de articulación del ámbito de actuación de las administraciones. No importaba tanto, por decirlo así, el debate sobre el volumen competencial y su adecuada distribución de cara a la mejor gestión de los servicios, sino que el poder local fuese autónomo del poder estatal y se aliviasen los controles gubernativos, que se ejercían habitualmente por vía de nombramientos y suspensiones administrativas. Este discurso es el que nos llega hasta la Constitución y las primeras elecciones municipales.

Junto a este modelo, la Constitución introduce el escalón autonómico, basado en otra lógica de descentralización que, partiendo de la estructura democrática general derivada del texto constitucional, se dirige esencialmente al reparto del poder entre el nivel estatal y el de los territorios autónomos.

Sin embargo, precisamente ha sido destacado por la doctrina ${ }^{2}$ cómo la aparición de este nuevo poder territorial se ha caracterizado por intentar expandirse, tanto más que sobre los poderes que el Estado ejercía en su territorio, sobre los poderes locales ubicados en el mismo. Precisamente Cataluña es el ejemplo paradigmático, de cómo el intento de interiorización del poder local como parte de su ámbito competencial exclusivo se ha conjugado con el intento de vaciamiento competencial y financiero de las Diputaciones Provinciales y con la desaparición de entes supramunicipales conurbanos como los existentes en el área metropolitana barcelonesa.

Quiero señalar con lo anterior que, de forma generalizada, la Administración autonómica, se ha mostrado con relación a la Administración local en la implantación del Estado autonómico, con el mismo espíritu invasivo con que lo hizo la Administración del Estado cuando, desde la construcción de la administración periférica, fue desplazando de la gestión de los servicios a la Administración local.

En modo alguno, la Administración autonómica ha partido de una interpretación de sus competencias como un poder limitado en su territorio por

2 Leguina, «Gobierno municipal y Estado Autonómico», RAP No 100. 
otra Administración, como la local. La Administración autonómica, con acertadas denuncias ${ }^{3}$, se ha pretendido a sí misma como la «administración única». Y es un hecho que el denominado Pacto Local, en cuanto descentralización de los poderes autonómicos en los poderes locales, ha sido impulsado, aun de manera deficiente, esencialmente por el Estado ${ }^{4}$.

Una parte relevante de la doctrina que ha estado atenta a este fenómeno ha realizado un importante esfuerzo de construcción dogmática para, desde las categorías de la garantía institucional y de la garantía constitucional de la autonomía local, instrumentar mecanismos de reacción que se han dirigido esencialmente a proteger a la autonomía local de su vecino autonómico más que del estatal.

Partimos, así de una experiencia de veinticinco años de modelo autonómico local, de la que se pueden extraer unos rasgos fundamentales:

- Se ha construido una autonomía local basada en la posición autónoma de los poderes locales respecto de los poderes autonómicos y estatales, derivada del principio democrático de elección de sus órganos de gobierno.

- Se han desarrollado en este sentido garantías efectivas respecto de los controles de oportunidad y legalidad de las Administraciones supraordenadas.

- No se ha conseguido, en cambio, una descentralización competencial en beneficio de los entes locales ni un sistema de suficiencia financiera.

- Entre la Administración autonómica y local no han funcionado de forma generalizada los mecanismos de colaboración y cooperación, sino que han tendido a construirse como realidades administrativas diferenciadas, aún actuando sobre los mismos ámbitos materiales.

- No se ha observado desde la legislación autonómica local una voluntad decidida por la defensa de los espacios competenciales locales ni por reforzar su configuración como entes dotados de autonomía política.

En definitiva, si el modelo actual sufriese una interiorización autonómica, se haría en una situación funcional de espacios competenciales mínimos donde la voluntad autonómica de constituirse en la «administración única»

\footnotetext{
${ }^{3}$ PAREJo, «Algunas reflexiones sobre el poder público administrativo, como sistema, en el Estado autonómico: una contribución al debate sobre la llamada Administración única», DA n ${ }^{\circ} 232-233$.

${ }^{4}$ Impulso que se continúa en estos momentos con el intento de ampliar el ámbito competencial de los Municipios desde el Proyecto de Ley de Bases de Régimen Local y de delimitar un ámbito cierto de competencias propias que expresen el contenido mínimo a nivel nacional de la garantía institucional de los entes locales.
} 
limitaría una descentralización local. No se interiorizaría una administración local potente y vigorosa en un modelo de gestión basada en la subsidiariedad, sino una administración local de la que se sigue desconfiando como ente político y de gestión alternativo al propio poder autonómico.

Por ello, la primera cuestión que cabría destacar es que no existen razones de peso para promover una interiorización y un cambio de modelo. Si algo tendría sentido, vista la experiencia de este periodo, sería introducir en una futura reforma constitucional, principios de ordenación y garantía del régimen local que permitan una activación más eficaz de los instrumentos de defensa de la autonomía local.

\section{LA DISCUTIBLE CONSTRUCCIÓN DE LOS ESTATUTOS DE AUTONOMÍA COMO SUBCONSTITUCIONES TERRITORIALES INTEGRANDO A LOS ENTES LOCALES COMO PARTE DE LAS INSTITUCIONES AUTONÓMICAS}

El segundo punto que me gustaría tratar es la propia concepción del Estatuto de Autonomía como el marco en el cual se deba regular con detalle el régimen jurídico propio de los entes locales.

La razón de ello es muy básica: los entes locales no forman parte del ordenamiento jurídico autonómico, sino que lo local se constituye como un ordenamiento propio relacionado con el estatal y el autonómico bajo el principio constitucional de autonomía.

En tal sentido, cada ordenamiento local tiene su propia colectividad política, distinta de la autonómica, con capacidad de expresión política diferenciada para la elección de su propia organización y la adopción de las decisiones de consulta popular que consienta la legislación.

La organización local, no se integra en la organización autonómica, sino que es propia de cada ente local, ligada y responsable ante su propia colectividad política y nunca ante la colectividad política autonómica. Esta organización amparada por la autonómica no esta nunca en una posición de sumisión jerárquica frente a la organización política autonómica y desarrolla los poderes propios de autoorganización y de dirección de su propio aparato administrativo en los términos del mismo principio de autonomía.

Está sometida a la ley, tanto estatal, como autonómica, que les puede encomendar tareas y obligaciones, pero que debe respetar en todo caso dicha posición de autonomía constitucionalmente garantizada.

No cabe, así, confundir el hecho de que la organización de un ordenamiento jurídico pueda servir de instrumento de otro ordenamiento jurídico con la 
RÉGIMEN LOCAL Y ESTATUTOS DE AUTONOMÍA

posibilidad de que una misma organización pertenezca a dos colectividades políticas, es decir, que esa organización sea, al mismo tiempo, la expresión de dos ordenamientos jurídicos.

La normativa local, es una expresión también propia del principio de autonomía, la cual aun debiendo respetar el marco normativo estatal y autonómico, debe poder en primer lugar, tener un ámbito de expresión del poder local, es decir, que sobre dicha normativa cabe afirmar dogmáticamente la reserva de un espacio normativo (una suerte de reserva reglamentaria) que no puede ser completamente invadido en ejercicio de la libertad del legislador estatal y autonómico. Pero, además, dicha normativa no es producto de la relación entre un ejecutivo y un legislativo del mismo ordenamiento, sino que se emana desde una posición de autonomía, por lo que tiene una naturaleza diferente de los reglamentos propios de una Administración vicarial. Expresan así una posición de orientación política que, aun sometida a la ley, no se controla desde el Parlamento autonómico, sino ante sus propios órganos de control político y, en último término ante su propia colectividad política.

Así como de la Comunidad Autónoma decimos que es Estado, en el sentido de que es poder público constitucionalmente reconocido, pero no por ello integramos a este ordenamiento en el del Estado, sino, al contrario, lo diferenciamos mediante una regulación propia contenida en cada Estatuto de Autonomía, también los entes locales, además de que son declarados desde la Constitución «Estado» a los mismos efectos de caracterizarlos como poder público, no por eso se integran en los espacios ordinamentales autonómico y estatal, sino que su propio espacio debe estar garantizado de una forma autónoma.

Éstas son a mi juicio razones de peso que abogan por una regulación de los entes locales fuera del instrumento institucional típico de las Comunidades Autónomas, el Estatuto de Autonomía, pues la integración local en las estructuras autonómicas siempre va en detrimento de la propia autonomía local. Así lo he querido demostrara en otro trabajo referido a la doble funcionalidad los Consejo Insulares ${ }^{5}$, como entes locales y entes auxiliares de la Comunidad Autónoma, que les hace ostentar a la postre una posición de autonomía inferior a las que les hubiese correspondido actuando como puros entes locales.

El Estatuto de Autonomía es la norma institucional del ordenamiento autonómico y por tanto, fuera de él y como garantía de su posición constitucional de autonomía, debe situarse la regulación del régimen jurídico de los entes locales.

La Constitución es muy clara en este sentido, tanto en los artículos 137, 140 y 141, que delimitan los entes locales como organización propia y aje-

5 «El régimen jurídico de las funciones y competencias de los Consejos Insulares en la Ley 8/2000, de 27 de octubre», en Los Consejos Insulares, Tirant lo Blanch. Valencia 2005. pp. 129 a 145. 
na a la autonómica, como en los mismos artículos 147.2 y 152.3 , que se refieren a los elementos que deben ser contenidos en los Estatutos de Autonomía, y donde sólo se regula la mera posibilidad de que los Estatutos, en correspondencia con el artículo 141.3, puedan establecer circunscripciones territoriales propias mediante la agrupación de municipios limítrofes, en clara alusión a la posible existencia de comarcas en determinadas comunidades autónomas.

Es distinto, sin embargo, concebir que los Estatutos puedan y deben contener las reglas de la forma en que tal ordenamiento se quiere relacionar con el ordenamiento local, introduciendo, por ejemplo:

- las formas de participación local en la adopción de las decisiones administrativas y normativas que les puedan afectar;

- los principios de subsidiariedad y proporcionalidad; un listado de las competencias autonómicas que son descentralizadas en los entes locales y las potestades administrativas necesarias para su ejercicio;

- órganos de colaboración y de coordinación competencial y funcional;

- la autorestricción normativa en determinadas materias propias, previendo que determinadas competencias legislativas autonómicas serán desarrolladas únicamente por ordenanza local;

- garantías de que la función inspectora de la Comunidad en modo alguno afecta a la autonomía de gestión de la propia organización local;

- la previsión de que los Defensores del Pueblo o los Síndicos de Cuentas autonómicos, ceden su función en relación a la Administración local cuando a nivel local se creen figuras de control semejantes;

- la garantía de la efectiva participación local en los impuestos autonómicos propios o cedidos;

- la eventual concesión de que en determinados supuestos las autoridades locales presidan actos donde se encuentren autoridades autonómicas;

y así un largo etcétera de supuestos en los que la Comunidad Autónoma abre su ordenamiento a la participación local o lo modula para consentir una mayor capacidad de intervención local en beneficio del principio de descentralización. Supuestos, además, que como veremos más adelante, en modo alguno afectan a la posición del legislador básico, ya que éste no podría disponer de la forma en que una Comunidad Autónoma modula su propio espacio institucional, competencial y normativo a favor de los entes locales de su territorio.

Éste es en realidad el verdadero mensaje de la Recomendación 121, de 14 de noviembre de 2002, sobre la democracia local y regional en España del 
RÉGIMEN LOCAL Y ESTATUTOS DE AUTONOMÍA

Congreso de los poderes Locales y Regionales de Europa. En él, en efecto, se destacan los siguientes puntos:

- la frecuente tendencia a que la legislación sectorial, particularmente la autonómica, realice una delegación de poderes más que una atribución de competencias propias ( F-9);

- la recomendación de introducir de forma explícita el principio de subsidiariedad en los Estatutos de Autonomía (F-13);

- la recomendación de establecer mecanismos de participación de las Autoridades locales en las decisiones de las Comunidades Autónomas que les afecten (H-1);

- la recomendación de establecer mecanismos de coordinación de políticas y actividades administrativas mediante los procedimientos apropiados para garantizar la posición de autonomía de ambas partes en dicha cooperación (H-3);

- la mención a que el Pacto Local se está desarrollando de forma dificultosa en materia de competencias y responsabilidades (I-1).

No se desprende, en cambio, de esta Recomendación una «regionalización» del régimen local español en el sentido de desplazar su regulación desde la instancia estatal a la autonómica.

En este sentido se señala:

- que la Constitución de 1978 no ha transformado a España en un Estado federal (E-6);

- que el poder normativo sobre los entes locales está compartido por el Estado y las Comunidades Autónomas, determinando el primero sus principales y uniformadoras características y decidiendo las segundas las peculiaridades locales (F-3);

- que expresa su satisfacción por el significativo papel jugado por el Tribunal Constitucional en la resolución de los conflictos competenciales entre el Estado y las Comunidades Autónomas (G-12);

- que considera que a largo plazo aumentarán los poderes regionales de regulación local dentro del respeto a los principios generales contenidos en la Constitución y la ley nacional como garantía de la autonomía local (I-8).

De todo lo anterior se puede concluir que esta Recomendación acepta plenamente el papel jugado hasta ahora por el legislador estatal con relación al régimen local (no hay ni una sola crítica en este sentido) y que la llamada a regionalización se refiere, en mayor medida, a los esfuerzos que deben ha- 
cer las Comunidades Autónomas para reformar sus ordenamientos, de forma que asuman que en sus territorios existen entes públicos territoriales que también están dotados de autonomía política y que ello exige una forma específica de relacionarse con ellos.

En este sentido el Proyecto de Estatuto de Cataluña, si bien recoge algunas medidas de las que anteriormente se han señalado de apertura de su ordenamiento a los entes locales ${ }^{6}$, también, y derivado del concepto de subconstitución territorial de que está penetrado todo su contenido, hace que se produzca una extensión regulatoria que va más allá de la propia organización de las instituciones de la Generalitat.

En primer lugar debe destacarse el artículo 2.3 que declara que los entes locales «integran el sistema institucional de la Generalidad» ${ }^{7}$, tenida cuenta de que el art. 2 se rotula «La Generalidad» y que en su apartado 1 se declara que: «La Generalidad es el sistema institucional en que se organiza políticamente el autogobierno de Cataluña». Se produce un salto, así, de considerar que los entes locales son territorios en los que se organiza la Generalidad, a determinar que son instituciones de la Generalidad, es decir, forman parte de la organización política propia de la Comunidad Autónoma.

El hecho de que en el artículo 71.1 se produzca implícitamente una diferenciación entre la Administración de la Generalidad y la Administración local no implica que, a tenor del artículo 2.3, ambas no se integren en la organización autonómica. No en vano, el Gobierno local aparece en el Capitulo VI dentro del Título de las Instituciones, que están formadas por el Parlamento, (cap.I), el Presidente/a de la Generalidad (cap.II), el Gobierno y la Administración de la Generalidad (cap.III), las relaciones entre el Parlamento y el Gobierno (cap.IV) y otras instituciones de la Generalidad (cap.V). Igualmente, las haciendas locales aparecen como Capítulo III dentro del Título VI dedicado a la «Financiación de la Generalidad».

Además hay una clara reiteración de estas manifestaciones, pese el cambio de sujeto y de articulación que recoge el artículo 83.1, cuando declara que «Cataluña estructura su organización territorial básica en municipios y veguerías». El municipio y la veguería se convierten, así, en parte de la organización territorial de Cataluña y en parte de la organización institucional de la Generalitat, que es, a su vez, el sistema institucional en el que se organiza

\footnotetext{
${ }^{6}$ Así sucede con relación a su participación en el proceso legislativo que les afecte (art. 62.1); a la defensa de la autonomía local por el Consejo de Garantías Estatutarias (art. 76.2.d); a los posibles acuerdos entre el Síndico de Agravios y los defensores locales de la ciudadanía (art.78.4); a la garantía de competencias propias (art. 84); a las funciones de participación del Consejo de Gobiernos Locales (art. 85) y a la reserva de ordenanza local en materia de organización y funcionamiento (art. 87.1).

${ }^{7}$ A fecha de 20 de febrero este precepto dice:

«3. Los municipios, las veguerías, las comarcas y los demás entes locales que las leyes determinen también integran el sistema institucional de la Generalidad, como entes en los que esta se organiza territorialmente, sin perjuicio de su autonomía».
} 
RÉGIMEN LOCAL Y ESTATUTOS DE AUTONOMÍA

políticamente Cataluña. Si nos fijamos, esta doble ligazón acumula los rasgos de identidad de ordenamiento, al identificarse la conexión con el territorio que es la base la organización política, y de dualidad de organizaciones, lo que coloca la organización local catalana en una posición impropia de su derecho a ser configurada como un ordenamiento propio.

En segundo término, esta pertenencia al sistema institucional implica que la organización local tiene una posibilidad de un control político y administrativo desde la organización autonómica, entendida en su conjunto institucional, que puede llegar a cobrar cuotas de gran intensidad y que se manifiesta en los siguientes aspectos:

- la obligación de las autoridades locales de Cataluña de comparecer a requerimiento del Parlamento (art.59.5);

- la posibilidad de crear comisiones de investigación sobre asuntos locales que sean considerados de relevancia pública y de interés de la Generalidad, con el consiguiente deber de comparecencia obligatorio ante las mismas (art.59.6);

- El Síndico de Agravios extiende sus funciones a la supervisión de la actividad de la Administración local de Cataluña y a la de los organismos públicos o privados vinculados que dependen de la misma (art. 78.1);

- La Sindicatura de Cuentas, con dependencia orgánica del Parlamento fiscaliza las cuentas, la gestión económica y el control de eficiencia de los entes locales de Cataluña (art.80.1).

El Estatuto de Autonomía, que en puridad debe servir para configurar los elementos propios del ordenamiento autonómico, sitúa, de este modo, a la Generalidad en una clara posición de predominio sobre los poderes locales de Cataluña que va más allá del mero predominio ordinamental y los hace aparecer, por tanto, concebidos como entidades insertadas en la propia organización política de la Generalidad.

\section{LA AMPLIACIÓN DEL MARCO COMPETENCIAL AUTONÓMICO EN MATERIA DE RÉGIMEN LOCAL MEDIANTE LA REMODELACIÓN DE LOS ESTATUTOS DE AUTONOMÍA}

El tercer aspecto que querría tratar es el relativo a la afirmación de que la amplitud de la legislación básica del Estado tendrá más o menos aplicación en base a lo dispuesto en cada territorio por su Estatuto de Autonomía.

Lógicamente el cometido de este trabajo no me permite entrar a fondo en 
esta cuestión, pero sí quiero dejar despejados algunos argumentos que me parecen fundamentales ${ }^{8}$.

Parto de entender que la relación entre los Estatutos de Autonomía y la legislación básica no es relación de jerarquía normativa, sino de adecuado reparto competencial. En ese sentido, ambos tipos de normas se desarrollan en ámbitos separados. La ley básica es servidora del espacio competencial reservada al Estado por la Constitución, del mismo modo que la ley de desarrollo lo es con relación al espacio competencial autonómico definido en el Estatuto?.

La ley básica actúa en el campo acotado y reservado por la Constitución a favor del Estado ${ }^{10}$. Cabe discutir si dicho campo es más o menos amplio, pero esa discusión no se establece entre ley básica y Estatuto, sino entre Constitución y Estatuto. Por eso, JIMÉnEZ CAMPO ${ }^{11}$ destaca, como una de las exigencias del propio concepto de norma básica, «el reconocimiento...del espacio de autodeterminación que corresponde a las instituciones generales del Estado — por haberlo querido así la Constitución - en la identificación de lo que se haya de tener por «básico» en cada sector material».

Como señala RuBio, «las normas básicas, se las entienda como se las entienda, no son normalmente reglas de delimitación competencial y no se integran, en consecuencia, en el bloque de la constitucionalidad. La delimitación competencial viene establecida en estos casos por la propia Constitución y no requiere norma ulterior alguna ${ }^{12}$. Igualmente, JIMÉNEZ CAMPO ${ }^{13}$ considera que «la competencia del Estado ex artículo 149.1 de la Constitución no es tanto, en estos casos, para regular ciertos ámbitos materiales cuanto para articular en ellos, definiendo la aplicabilidad de las propias normas, el Derecho estatal y el autonómico»

El artículo 149.1 en sus distintos apartados no está configurado con una dimensión variable que se hace depender del contenido estatutario, no pue-

\footnotetext{
${ }^{8}$ Me remito en este sentido a mi trabajo Legislación básica y Estatutos de Autonomía. CEPC. Madrid. 2006 (en prensa)

${ }^{9}$ JiMÉNEZ CAMPO señala en este sentido: «las competencias estatales y autonómicas así llamadas a disponer, complementándose la íntegra regulación de un cierto objeto son, claro está, exclusivas de cada ente en su ámbito propio». «¿Qué es lo básico?. Legislación compartida en el Estado Autonómico». $R E D C \mathrm{n}^{\circ} 27,1989$, p. 40.

${ }^{10}$ Leguina señala en este sentido que «la reserva de una potestad legislativa al Estado en un amplio elenco de materias, que obliga a éste a compartir ese poder de legislar...con las Comunidades Autónomas, conforme a lo que dispongan en cada caso sus respectivos Estatutos, significa que el poder de legislar se artícula, como es bien conocido, sobre el principio de competencia». «El poder legislativo en el Estado Autonómico», en Escritos sobre Autonomías Territoriales, $2^{a}$ ed. Tecnos. Madrid, 1995, p. 166

${ }^{11}$ Op.cit., p. 43.

${ }^{12}$ Rubio, «El bloque de la constitucionalidad». REDC No 27, 1989, p. 31.

${ }^{13}$ Op.cit., p. 92.
} 
RÉGIMEN LOCAL Y ESTATUTOS DE AUTONOMÍA

de asumirse, así, la afirmación de que la amplitud de la legislación básica del Estado tendrá más o menos aplicación en base a lo dispuesto en cada territorio por su Estatuto ${ }^{14}$. La prueba de ello es que si se suprimiese el principio dispositivo con relación a las competencias autonómicas y la Constitución atribuyese directamente a las Comunidades Autónomas lo no reservado al Estado por el 149.1, los eventuales excesos de la legislación básica serían siendo una vulneración de la Constitución. Por ello, si a través de la ley básica el Estado ocupa el lugar que le está reservado por la Constitución, lo dispuesto por el Estatuto no puede alterar lo básico, pues de hacerlo supondría de forma inherente una vulneración de la Constitución misma.

La Constitución no exige la subordinación de la legislación básica a los Estatutos, ya que la eventual discrepancia entre estas normas se tiene que resolver mediante la interpretación de la Constitución, en el sentido de que si lo básico es amparado por la interpretación de la Constitución, debe ceder lo dispuesto en los Estatutos ante esta interpretación. Ya señalaba DE Отто ${ }^{15}$ que «a la hora de examinar la titularidad o el alcance de las competencias debatidas en un proceso constitucional el Tribunal Constitucional ha de tener en cuenta en primer lugar la Constitución y luego los preceptos estatutarios, que sólo se aplicarán si son conformes con la norma constitucional o susceptibles de interpretarse de conformidad con las prescripciones constitucionales». Igualmente SOLOZÁBAL ${ }^{16}$ manifiesta que «las atribuciones competenciales dependen de determinaciones estatutarias, pero teniendo en cuenta la existencia de normas interpuestas entre la Constitución y los estatutos que modulan la atribución estatutaria.

Lo mismo sucede en ausencia de una legislación básica expresa, donde se impone el concepto material de lo básico como un límite a la autonomía, pero es un límite que deriva directamente de la Constitución. Esa ausencia de legislación no le permitiría, así, al Estatuto disponer que el legislador de desarrollo pueda ocupar todo el campo, pues como señala JIMÉNEZ CAMPO ${ }^{17}$, «en ausencia de una precisa determinación política de lo que sea básico, las disposiciones autonómicas siguen condicionadas por el Derecho del Estado (siguen siendo ejercicio de una competencia de desarrollo)».

\footnotetext{
${ }^{14}$ Sí existen otros supuestos en los que, en cambio, existe un juego Estatuto-legislador estatal. El primero de ellos es cuando, en virtud del principio dispositivo, el Estatuto no ocupa todo el campo que le ésta reservado en la Constitución y provoca la puesta en marcha de la cláusula residual a favor del Estado, lo que puede hacer que se amplíe el ámbito de lo regulado por el Estado, aunque en puridad tal ampliación no tendría la condición de normativa básica.

${ }^{15}$ De Отто, Derecho constitucional y sistema de fuentes. Ariel. Barcelona, 1988, p. 267.

${ }^{16}$ «El Estado autonómico: bases y perspectivas», en La experiencia constitucional (1978-2000). CEPC, 2000 , p. 542.

${ }^{17}$ Op. cit., p. 92.
} 
La verdadera eficacia de la legislación básica no actúa por tanto en relación con la norma estatutaria, de aquí que es absurdo un planteamiento de «blindaje» de sus competencias respecto al legislador básico, ya que tales competencias aparecen indisponibles por la propia naturaleza del Estatuto como norma supraordenada. La legislación básica donde actúa es con relación a la legislación autonómica de desarrollo. RuBIO ${ }^{18}$ lo dice claramente: «la función necesaria de lo básico es, justamente establecer el marco de desarrollo».

Derivación de lo anterior sería la segunda tesis, ya señalada, según la cual la legislación básica del Estado en materia de régimen local tendría una aplicación diferente según lo que dispusieran los distintos Estatutos de Autonomía. Dicha tesis se ampara ciertamente en algunas sentencias del Tribunal Constitucional que han matizado el alcance alguna disposición básica en función de determinadas previsiones estatutarias. Sin embargo, estas sentencias son escasas y unas se derivan de excepciones realizadas por la propia Constitución (derechos de territorios forales) y en otras la propia norma básica contemplaba la excepción.

En todo caso, lo que se puede cuestionar es el propio contenido básico de dichas normas estatales en sí. Es decir, si legítimamente, de acuerdo con la interpretación de la Constitución, una materia es encuadrable en las competencias autonómicas y así lo recogen los Estatutos, el hecho de que el Estado haya emanado una norma básica con un determinado alcance, incluso desde un título material diferente o desde varios títulos competenciales, y que el TC haya interpretado que tal alcance no sea aplicable en determinadas CCAA, puede significar simplemente que algunos aspectos de la dimensión de lo básico, no son tales, lo que sucede es que, al no estar acotado tal ámbito como competencia autonómica en el resto de los Estatutos, el Estado ocupa ese espacio normativo. Pero en esta lógica, una equiparación estatutaria haría que tal aspecto, que no es en sí básico, sino derivado de la resiualidad, desapareciese.

Caso diferente es que la Constitución o la pura realidad fáctica haga que determinadas normas estatales sólo tengan aplicación en una parte del territorio. Sería el caso de la regulación del uso de la lengua castellana en el sistema educativo, que podría ser articulada como básica aunque determinados aspectos de la misma tuviese una aplicación diferente para los territorios que no tuviesen una segunda lengua cooficial o las reglas básicas ambientales sobre la protección de las costas.

En el mismo sentido se manifiesta LÓPEZ GUERRA ${ }^{19}$, el cual parte de admitir que un Estatuto pueda asumir facultades que se definirían como no básicas y

\footnotetext{
${ }^{18}$ Op.cit., p. 31.

${ }^{19}$ LÓPEZ GUERRA, «La función constitucional y el contenido del Estatuto de Autonomía», en Estudios sobre la reforma del Estatuto. IEA. Barcelona, 2004, p. 41 y 42.
} 
RÉGIMEN LOCAL Y ESTATUTOS DE AUTONOMÍA

quedarían excluidas de la competencia estatal. Se basa para ello en la STC 109/ 98, en la que se estimó que «junto al régimen básico aplicable a la generalidad de las comunidades autónomas, coexistan situaciones particulares, aunque como es palmario, estas excepciones precisan ineludiblemente, bien una expresa habilitación constitucional... bien....un específico anclaje estatutario», pero para LÓPEZ GUERRA esta excepción es posible, porque las materias excepcionadas no deben entenderse incluidos en el concepto de bases estatales.

Además, para este autor, la excepcionalidad de la aplicación de lo básico sólo encuentra su fundamento en el hecho de que la Comunidad Autónoma, cuyo Estatuto realiza la exclusión, «no participa de las características que justifican la aplicación de una regulación uniforme («básica») en todo el territorio nacional» ${ }^{20}$. De aquí que ni cabe una generalización de estas excepciones, ni la presencia de las mismas en modo alguno puede obstaculizar la propia competencia estatal de dictar una normativa básica: «constituiría un fraude constitucional...que el Estatuto de Autonomía, al asumir competencias concretas en una materia cuyas bases se reservan al Estado, viniera a vaciar la potestad de éste para establecer las bases de la materia».

Se ha sostenido ${ }^{21}$, sin embargo, que la razón por la cual el Tribunal Constitucional ha interpretado la amplitud del artículo 149.1.18, en materia de régimen local, especialmente en la STC 32/1981, ha sido porque tal amplitud no había sido contrarestada por el Estatuto de Autonomía de Cataluña, en concreto por su artículo 9.8. en el que se asume la competencia exclusiva en materia de régimen local, pero entendiendo dicha exclusividad «sin perjuicio de lo que dispone el número 18 del apartado 1 del artículo 149 de la Constitución». Se sostiene, así, que si hubiese sido otra la redacción del Estatuto, hubiese sido otra la interpretación del Tribunal Constitucional acerca de las competencias estatales y autonómicas sobre el régimen local.

Por acudir al mismo ejemplo que plantea VelasCo, tomemos la STC 32/ 1981, de 28 de julio. Esta Sentencia se dicta con anterioridad a la propia Ley Reguladora de Bases de Régimen Local y en ella se construye buena parte de la interpretación constitucional de la extensión del título competencial del Estado sobre «las bases del régimen jurídico de las Administraciones públicas» contenido en el art.149.1.18 , en la que en nada influye, a mi juicio, la redacción contenida en el artículo 9.8 del Estatuto de Autonomía de Cataluña ${ }^{22}$.

\footnotetext{
${ }^{20}$ Continúa así diciendo LóPez GuerRa: «En otras palabras, esa exclusión (y tratamiento «especial» de una comunidad autónoma al respecto) debe derivar de la efectiva presencia de especialidades (organizativas, lingüísticas o de otro tipo) recogidas en el Estatuto que representen causa razonable suficiente para modular la extensión de lo básico en esa comunidad y en esa materia».

${ }^{21}$ Francisco Velasco, «Organización territorial y régimen local en la reforma del Estatuto de Cataluña: límites constitucionales», en Estudios sobre la reforma del Estatuto. Instituto de Estudios Autonómicos. Barcelona, 2004, pp. 283 y ss.

${ }^{22}$ Art. 9.8 Est.Cat.: «La Generalidad de Cataluña tiene competencia exclusiva sobre las siguientes materias: ...Régimen local, sin perjuicio de lo que dispone el número 18 del apartado 1 del artículo 149 de la Constitución...»
} 
En efecto, en la STS 32/1981 lo que se interpreta, entre otros asuntos, es el ámbito de la competencia estatal para establecer las bases del régimen jurídico de las Administraciones públicas.

La interpretación contenida en esta sentencia es importante ya que sigue siendo la clave de buena parte del sistema constitucional de Administración local y tiene dos elementos fundamentales en los que en nada influye, a mi juicio, ninguna redacción estatutaria.

El primer elemento es la construcción del apartado 18 como un título competencial especial dentro del art.149.1 (como una excepción lo califica el T.C.) y la especialidad se basa en que, al regular el Estado las bases del régimen jurídico de las Administraciones públicas, no regula un sector de actividad concreto, sino que realiza una reflexión sobre la forma de articulación del conjunto del aparato administrativo. Dice así el Tribunal:

«... es a primera vista evidente que la larga enumeración de competencias exclusivas del Estado (en el sentido más restringido del término) que hace el apartado primero del artículo 149 de la Constitución está construida por referencia a materias o actividades concretas del poder respecto de determinados fines sociales. Con la única y notable excepción precisamente del apartado 18, en la que la referencia es justamente a una acción por así decir reflexiva del Estado, esto es, a la que él mismo lleva a cabo en relación en relación con el aparato administrativo que constituye su instrumento normal de actuación».

Se trata, por tanto, de una reflexión que no podría venir condicionada en base a las diferentes excepciones que de lo básico se pretendiesen contener en cada Estatuto de Autonomía, ya que en tales términos tal reflexión no podría ser realizada y, en consecuencia, se dejaría sin contenido a la peculiaridad misma del punto 18 tal como ha sido interpretado por el Tribunal Constitucional.

El segundo elemento es la relación de esta peculiaridad contenida en el apartado 18 del artículo 149 con la garantía constitucional de la autonomía local, y no con ninguna norma estatutaria. Dice así el T.C. en este punto:

«Esta peculiaridad es importante ya que entronca con el tema de la garantía constitucional de que antes tratábamos. Como titulares de un derecho a la autonomía constitucionalmente garantizada, las comunidades locales no pueden ser dejadas, en lo que toca a la definición de sus competencias y la configuración de sus órganos de gobierno, a la interpretación que cada Comunidad Autónoma pueda hacer de este derecho...La garantía constitucional es de carácter general y configuradora de un modelo de Estado y ello conduce, como consecuencia obligada, a entender que corresponde al mismo la fijación de los principios o criterios básicos en materia de organización y competencia de general aplicación en todo el Estado». 
RÉGIMEN LOCAL Y ESTATUTOS DE AUTONOMÍA

Ésta es la interpretación esencial de la competencia del Estado sobre las bases del régimen local, cuya variación no está, como vemos al alcance de ningún Estatuto.

Como el propio T.C. dice en la misma sentencia: «Las Cortes deberán establecer que es lo que haya de entenderse por básico, y en caso necesario será este Tribunal el competente para decidirlo, en su calidad de intérprete supremo de la Constitución».

En el actual Proyecto de Reforma del Estatuto de Cataluña teniendo en cuenta la redacción del Texto de la Ponencia de 7 de marzo de 2006, no se altera, a mi juicio, en lo sustancial la situación actual.

El art. 160. 1 del Proyecto atribuye ${ }^{23}$ a la Generalidad «la competencia exclusiva en régimen local que, respetando el principio de autonomía local, incluye», a lo que siguen una serie de contenidos que reputan propios de dicha competencia exclusiva.

El apartado 2 del art. 160 dispone a su vez, «Corresponde a la generalidad la competencia compartida en todo lo no establecido por el apartado 1».

A mi juicio, esta nueva redacción, comparada con la del actual 9.8, puede ser es incluso más limitativa del ámbito autonómico, al incluir expresamente el respeto al principio de la autonomía local.

Así, pese a lo establecido en al apartado 1 de calificar el régimen local como competencia exclusiva, no invalida la interpretación del T.C. del artículo 149.1.18 que acabamos de ver, en cuanto que atribuye un título competencial al Estado en materia de régimen local que tiene su aplicación en la regulación del sistema competencial y organizativo de los entes locales, precisamente por su relación con el principio de autonomía local. Estamos, así, como en el caso anterior, en un supuesto de competencia compartida, en la que incluso aparece reforzada más la posición del Estado.

Debe recordarse a este respecto, con relación a las pretendidas competencias exclusivas estatutarias, que la STC 20/88 establece una doctrina muy clara del necesario matiz interpretativo que deben pasar los enunciados estatutarios en materia competencial:

«...la calificación jurídica que las competencias de las Comunidades Autónomas deben merecer no deriva de una lectura aislada de la denominación que tales competencias reciban en los textos estatutarios, sino de una interpretación sistemática de todo el bloque de la constitucionalidad, dentro del cual, como es evidente, la Constitución conserva intacta su fuerza normativa dominante como lex superior de todo el ordenamiento; fuerza normativa que no se agota ni disminuye con la

${ }^{23}$ Con una redacción manifiestamente mejorable. 
promulgación de los Estatutos de Autonomía, cuyos preceptos, por más que califiquen como exclusiva la competencia asumida ratione materiae, nada pueden frente a las normas constitucionales, que, en su caso, reconozcan al estado títulos competenciales sobre la misma materia».

Evidentemente todo lo dicho es aplicable a las reformas estatutarias.

En definitiva, a mi juicio, la interiorización del régimen local por los Estatutos de Autonomía tiene su pleno sentido en la apertura del ordenamiento autonómico a la participación local en su ámbito de ejercicio de poderes públicos, pero ello no debe abocar a una reforma de la posición ordinamental del régimen local basado en la autonomía de su propio ordenamiento.

Igualmente, las reformas estatutarias no deben ser pensadas como un vehículo para reinterpretar los títulos competenciales contenidos en la Constitución, pues ello implicaría situarse en posición de legislador constituyente y en desconocer la posición del Tribunal Constitucional como supremo intérprete de la misma. 